\title{
Ética en la Obra de Pioneros de la Psicología: ¿Metafísica o Política?
}

\section{Ethics in the Work of Pioneers in Psychology: Metaphysics or Politics?}

\author{
Ximena Wolff \\ María Isabel Reyes \\ María Inés Winkler \\ Katherine Alvear \\ Universidad de Santiago de Chile
}

\begin{abstract}
El desarrollo de la disciplina en sus 30 primeros años contextualiza este estudio historiográfico que indaga en la obra de seis pioneros de la Psicología en Estados Unidos (William James, Stanley Hall y James Mark Baldwin) y Chile (Sergio Yulis, Salvador Cifuentes y Hernán Larraín). Se realizó un análisis inductivo principalmente a partir de fuentes primarias y, en el caso de los chilenos, también de fuentes secundarias. Las dimensiones de Ética y Política, expresadas en sus reflexiones y posiciones permiten concluir que la larga tradición escritural y filosófica de los angloparlantes (heredera de una ética protestante) contrasta con la escasa producción de los chilenos, observable en su práctica como experiencia fundamental de su exposición moral (legado de la tradición oral cristiana). Características del desarrollo de la disciplina y la obra de cada pionero se eclipsan ante la influencia del contexto socio-histórico.
\end{abstract}

Palabras clave: historia de la psicología, ética, politica, Estados Unidos, Chile.

\begin{abstract}
The context of this historiographic research is the development of psychology during its first 30 years. We focused on the work of six of psychology's pioneers, three from the USA (William James, Stanley Hall, and James Mark Baldwin) and three from Chile (Sergio Yulis, Salvador Cifuentes, and Hernán Larraín). An inductive analysis was performed using mostly primary sources, and in the Chilean case, secondary sources were also used. Ethical and political dimensions, manifested in their reflexions and perspectives, allowed us to conclude that the long written and philosophical tradition of USA researchers (inherited from protestant ethics) contrasts with the sparse productivity of its Chilean counterparts, present in their practice as a fundamental experience of their moral exposure (inherited from Christian oral tradition). Thus, characteristics of the development of the discipline and the work of each pioneer is eclipsed by the influence of the social and historical context.
\end{abstract}

Keywords: history of psychology, ethics, politics, United States, Chile.

¿Sabes que... han quemado mis libros y me han declarado un ateo porque me opongo a la guerra de Vietnam? Es completamente increíble. Este país está loco de odio, frustración, estupidez, confusión" Thomas Merton.

Esta investigación, en la confluencia de dos temáticas de plena actualidad -ética y género- rastrea las huellas de pioneros en los orígenes de la Psicología como ciencia y profesión, en un recorrido que nos transporta a los 30 años inaugurales de la disciplina en Chile y Estados Unidos.

Ximena Wolff Reyes, Escuela de Psicología, Universidad de Chile. Chile.

María Isabel Reyes Espejo, Escuela de Psicología, Universidad Santo Tomás y Universidad de Santiago de Chile. Chile.

María Inés Winkler Müller, Académica Escuela de Psicología, Universidad de Santiago de Chile. Chile.

La correspondencia relativa a este artículo debe ser dirigida a María Inés Winkler, Escuela de Psicología, Universidad de Santiago de Chile. Av. Ecuador 3650 Estación Central, Santiago, Chile. Email: mariaines.winkler@gmail.com
$\mathrm{Al}$ abocarnos a la cuestión de la ética nos apoyamos en la posición crítica de Maritza Montero, quien la señala junto con la política como dos dimensiones no reconocidas en la concepción paradigmática tripartita de la Psicología, sólo "presentadas como accesorios dignificantes" (Montero, 2001, p. 2) y que dejan fuera de apreciación el juicio y la distinción entre el bien y el mal, así como la concepción del Otro y su lugar en la producción del conocimiento, excluyendo las preguntas de ¿quién habla?, ¿quién es el Otro?, ¿cuál es su lugar? y ¿quién conoce?.

Montero (2001) diferencia ética y moral, señalando que la primera supone una reflexión general de carácter social, relacional, de la cual derivan los mandamientos específicos que cada persona deberá implementar en su vida cotidiana. La moral deviene el conjunto de prescripciones, de normas, en una época y en una sociedad o cultura determinadas. No son intercambiables: el conjunto de reglas a observar en pro de una conducta moralmente intachable no necesariamente es ético. Asimismo queda excluida 
la cuestión política relativa a la vida organizada colectivamente y, fundamentalmente, para quién es el conocimiento, quién será su poseedor o propietario, a quién sirve el conocimiento psicológico.

Ya no es posible pensar la subjetividad y/o sus efectos sociales como un producto que poseería la plenitud del conocimiento de sí y de sus determinaciones, pues aparece sólo como sujeto y soporte de situaciones, ante las cuales responde desde el campo privilegiado de la relación con el Otro, que otorga "ser" a cada sujeto como punto re-flexivo, expuesto ante los otros, inmerso en el paradigma del diálogo moral (Giannini, 1997).

El ser ahí ante-otro arrastra siglos de con-formación, en conformidad con una lógica constructiva de código binario en toda comunidad histórico-parlante al circular en los significados y las referencias: pasivo-activo, sagrado-profano, racional-emocional, hombre-mujer, etc., donde las teorías sociales, por su parte, como reproducción ideológica de estas distinciones narran una historia dramática que apela a las personas a tomar partido e instalan un referente que ordena lo social a la vez que lo orienta (Lechner, 2002).

Supusimos que la participación de los pioneros en el surgimiento de la Psicología como profesión se articuló tanto a los pasos teóricos necesarios, como también marcó sus juicios como "agentes morales activos", ajenos a la neutralidad o indiferencia valórica.

En este reporte consideraremos sus posiciones en relación a la libertad humana tal como la resitúa Hannah Arendt: "garantizada básicamente por la capacidad de decir sí o no a lo que venga dado de afuera" (citado en Cano, 2000, p. 9) y entendiendo la política como la organización libre para atender intereses públicos, distinta de la actividad maquiavélica y del ejercicio exclusivo del gobierno o la administración 'autorreferencial'.

Exponemos los trabajos de pioneros de ambos países, sus reflexiones y posiciones, preguntándonos ¿Qué códigos, referencias, significados, voluntades o deseos asumen? ¿Desde cuáles representaciones?

\section{Antecedentes: La 'Prehistoria' e Historia de América}

Los territorios 'descubiertos', conquistados y colonizados en los siglos XV y XVI comparten una prehistoria europea cuya matriz se remonta al término de la Edad Media y a una historia inaugurada con el monumental cisma de Occidente que culmina con la escisión de la Iglesia. Lutero concitará la cohesión de aquellos que hacen un juicio moral a las prácticas 'mercantiles' de la Bula de las Indulgencias y rechazan la corrupción eclesiástica, apelando a la capacidad individual para ejercer la conciencia e interpretar una Biblia traducida a la lengua nativa por el propio Lutero y difundida por la reciente imprenta. La Reforma que se despliega arrastra no sólo cuestiones religiosas, denunciando la connivencia del papado italiano con los poderes terrenales de reyes y emperadores, amén de los múltiples señoríos que subordinan a campesinos y burgueses. Las guerras se extenderán en el juego por el dominio del poder.

La sustitución del pensamiento medieval, feudal, y la creación de una mentalidad propia de la modernidad determinarán condiciones y destinos diferentes en las colonias de las Américas (Morse, 1982). De este cisma emerge también una continuidad renovada: los jesuitas ofrecen su misticismo, su espíritu de caballeros andantes para defender la fe contra los herejes luteranos, calvinistas, anglicanos y la Compañía surge como una organización militante, encabezada por un general que ha jurado fidelidad y obediencia absoluta al Papa y a Roma. Así, la Reforma y Contrarreforma tendrá enormes consecuencias en los territorios por conquistar y colonizar, no sólo en América sino también en África y Asia (Buelna, 1990).

El nacimiento del Nuevo Mundo, su Conquista y Colonización, aquella primera globalización, trae creencias, esperanzas, promesas, ambiciones y formas de organización y confrontación imperantes en las metrópolis europeas de efectos mayúsculos en el destino de América.

Entre la América anglosajona y la hispánica aparece una primera gran diferencia en relación a los "conquistados": las poblaciones indígenas del Norte habían poblado las costas del Este y eran grupos tribales que no constituían Estados, siendo relegados hacia el oeste árido, convirtiéndose en grupos nómades y guerreros (Buelna, 1990).

También la diferencia atañe a los "conquistadores". El área angloparlante recibió durante el siglo XVII la enorme afluencia de familias de inmigrantes europeos y puritanos ingleses que huían de las persecuciones a causa de su credo, caracterizado por su fuerte sentido del pecado y dogmatismo, que instalará en el centro de la vida angloamericana de la cuestión moral y libertad de conciencia.

Los colonos reciben tierras, pero "Nueva Inglaterra" no era territorio deshabitado y su apropiación 
se hará declarando el área 'vacía' legalmente: "Sin capacidad de esclavizar a los indios ni tampoco de vivir con ellos, los ingleses decidieron exterminarlos" (Morgan citado en Zinn, 2003, p. 13). Se postula el origen democrático de toda autoridad religiosa, suprime ceremonias, niega la tradición y el dogma de la predestinación, reduciendo los sacramentos al bautismo y la cena: inmejorables condiciones para permanecer aislados en labores cotidianas sin mediación de una Iglesia central.

El modo de vida, simple y frugal, el trabajo concebido como fin en sí mismo y forma divina de placer debe ser realizado en forma metódica y racional; la riqueza - señal de la bendición de Dios- debe ser bien administrada y el lucro es fruto del esfuerzo y muestra del agrado de Dios por el trabajo. En esta visión optimista buscar el propio interés mejora las condiciones generales y el tesón debería -eventualmente- producir un cielo en la tierra.

Después de la Guerra de Secesión (1861-1865), Estados Unidos comienza una época de gran expansión económica con efectos morales y éticos. El explosivo crecimiento de la población, la llegada de nuevos inmigrantes aporta mano de obra barata y los continuos avances científicos al servicio del aumento de la producción, abren la posibilidad y el afán por nuevos mercados, consolidando el desarrollo del capitalismo.

Según Zinn (2003) casi 20 millones de inmigrantes llegan en las décadas de 1880-1890, más desprotegidos que los trabajadores nativos; desplazados culturalmente eran controlables y utilizables como rompe-huelgas ante las demandas laborales. Más tarde, la aplicación del Taylorismo hará partícipe a la psicología en la automatización del trabajo.

Hacia finales del siglo XIX la ética protestante es cuestionada. Surge un movimiento contra el tradicionalismo que apela a la ética social de la mano con el desarrollo filosófico del pragmatismo. El énfasis en la utilidad contribuyó a este nacimiento y produjo cambios en las organizaciones sociales. Esta semilla pragmatista toma fuerza más tarde, cuando la ética protestante retrocede definitivamente y las Postguerras muestran que no todo lo útil ni todos los pragmatismos nos convienen éticamente.

De otra parte, Iberoamérica, territorio que queda bajo el dominio de la Contrarreforma, conocerá el orden temporal y espiritual del Gobierno de Indias; es decir, de las leyes que rigen tanto sus derechos políticos como la pastoral de sus almas.

Aquí, en la multiplicidad de etnias, los conquistadores encuentran grandes civilizaciones, "Estado-
Imperios" 'paganos', que serán desarticulados y "convertidos" en provisión de todo tipo de bienes y recursos para la Casa de los Habsburgo y luego para los Borbón.

Una articulación colosal de Cruz y Espada implica 6 millones de indios ya bautizados a la llegada de la Compañía de Jesús a la Nueva España (México) en 1572, por sus antecesores franciscanos, dominicos y agustinos (Buelna, 1990). La oposición entre la concepción pagana de la vida y el mensaje evangélico debía desaparecer con la instrucción bajo un modelo renacentista, regido por los lemas romanos de prudencia, justicia, fortaleza y templanza sumados a las virtudes teologales de fe, esperanza y caridad. Su eje fundamental será la subordinación jerárquica y la exaltación de la obediencia (Gonzalbo, 1990).

Los Ejercicios Espirituales de la nueva actitud católica combinan elementos psicológicos e intelectuales para implantar en corazones y mentes un mensaje teológico envuelto en recursos afectivos: la devoción y culto a la Virgen María, la confesión obligatoria y la comunión responderán al individualismo protestante.

La Compañía de Jesús llega a Chile en 1593 y en su deseo de encarnación busca darse a entender al pueblo, asume su lengua, estudia sus costumbres para inculcar la fe y entablar un diálogo al "escudriñar con benevolencia y con respeto la parte de verdad que hay en el otro" (Espíndola, 1993, p. 178); da la comunión a los nativos y evangeliza a los indígenas esclavizados, tratándolos como personas. Renuncia a tener esclavos e inventa en Chile la previsión social (1608) recibiendo fuerte rechazo de parte de los encomenderos que dejan varios mártires jesuitas.

Después de un siglo, la orden tiene poder. Al segundo centenario, ante la animosidad por ser vistos como baluartes de la Iglesia, reciben la fuerte oposición de un racionalismo laicista y anticlerical. Expulsados en 1767 de todos los dominios de la monarquía española y restaurados por Pío VII en 1814, su retorno a Chile se concretará en 1848, aunque obtienen reconocimiento legal recién en 1940 (Leturia, 1993).

Entre sus obras: el Hogar de Cristo (1944); la revista Mensaje (1951); se hacen cargo de la Universidad Católica (1958) y del Centro Bellarmino. Jesuitas norteamericanos de Maryland llegan a Osorno (1960), con "un aporte muy poco hispano que agilizó la vida científica y productiva" (Leturia, 1993, p. 210). 
Paralelamente, diferentes congregaciones se preguntarán acerca del papel de la Iglesia en asuntos mundanos y en sus luchas a favor de los pobres. El Concilio Vaticano II, la Teología de la Liberación, el Movimiento Camilo Torres y la Declaración de Puebla traerán al terreno político opiniones emitidas desde el púlpito, interviniendo en cuestiones tales como las propiedades terrenas y su posesión.

Por otra parte, el racionalismo laicista y republicano tendrá una incidencia perdurable, postulando la emancipación de la filosofía y la moral respecto de la religión positiva que, desde el siglo XVII, marca su pensamiento político y que ha hecho predominar la razón por sobre el misterio, en rechazo de la verdad revelada.

La concepción de un Estado laico sostiene la autonomía de las instituciones públicas y la sociedad civil respecto del magisterio eclesiástico y la injerencia de las organizaciones confesionales. El régimen de separación jurídica entre Estado e Iglesia garantizará la libertad de los ciudadanos respecto a ambos, postulando una libertad de culto apoyada también por confesiones minoritarias (Bobbio \& Matteucci, 1982).

En Chile, el movimiento laico adquiere importancia creciente cuando los gobiernos radicales se dedican a la secularización por la vía de la educación laica y estatal.

La Psicología chilena, surgida en la post guerra se inscribió en el 'fatum' ya hecho de dos explosiones atómicas y enmarcada entre dos acontecimientos literarios nacionales: Gabriela Mistral ha recibido el Premio Nobel de Literatura en 1945 y 27 años después (1972) lo hará Pablo Neruda.

Los primeros cursos de psicología, destinados a profesores exceden todas las expectativas, y la guerra que ha dispersado otros pueblos por el planeta, traerá a los emigrantes europeos por segunda vez a un lugar republicano para sus oficios: las Américas. Son fugitivos o sobrevivientes de campos de concentración, aportarán a los desarrollos profesionales en docencia, formación y práctica profesional.

\section{Método}

Nuestro objetivo es identificar, desde una perspectiva histórica, las relaciones entre ética, producción teórica y ejercicio profesional de la psicología, comparándolas en sus primeros treinta años en Estados Unidos de Norteamérica: de 1883-1913, al considerar la creación del Primer Laboratorio de Psicología por Stanley Hall como el hito fundacional de la disciplina en aquel país; y de 1946-1976 para Chile, cuyo límite inferior evoca la creación del Departamento de Psicología en la Universidad de Chile (1947).
La muestra de pioneros estadounidenses está compuesta por William James, Stanley Hall y James Mark Baldwin; y para el caso chileno, Sergio Yulis, Salvador Cifuentes y el sacerdote jesuita Hernán Larraín.

Optamos por un diseño de investigación con metodología cualitativa, utilizando la teoría fundada empíricamente propuesta por Glasser y Strauss (1967; Strauss \& Corbin, 1994), realizando una leve modificación al método, en tanto el acceso a la información estuvo acotado por las fuentes disponibles, para enfatizar descriptivamente los aspectos de nuestro interés más que "agotar" la búsqueda de información como lo requiere el método al aplicarlo a situaciones actuales.

Confeccionado el corpus de las obras disponibles, se procedió al análisis del material en las dimensiones primarias de procesamiento que permitieron elaborar fichas bibliográficas para cada uno de los autores. De esta manera, se identificó cuantitativa y cualitativamente la presencia de las temáticas de ética en la producción teórica y/o investigación básica, profundizando prioritariamente en la postura teórica e ideológica de los seleccionados, las áreas específicas de desempeño y en su contexto histórico, para reconstruir sus fundamentos y preocupaciones éticas.

\section{Resultados}

\section{Estados Unidos (de Norteamérica): Primera Trilogía}

Comenzaremos con el padre del Pragmatismo estadounidense, William James; ahondaremos en los planteamientos evolutivos de Granville Stanley Hall para finalizar con James Mark Baldwin y su obra en la Filosofía y Psicología del Desarrollo Moral.

William James (1842-1910). Un concepto clave en el sistema pragmático de James es el de Verdad: las ideas verdaderas son aquellas que podemos asimilar, validar, corroborar y verificar. Cercano se encuentra también el de ética: lo que es bueno es lo que conduce eficazmente al logro de un fin y lleva al éxito. Los valores, principios y normas carecen de un contenido objetivo pues el valor de lo bueno varía con la situación.

James (1892) dejará fuera la cuestión ética por ser "metafísica", ajena a esta ciencia natural dedicada al estudio de la conciencia que entrama en el sumiso laberinto de la formación de hábitos.

Sin embargo, su participación política nuevamente se dirige al ámbito ético-político: es uno de los creadores de la Liga Antiimperialista, se opone a la anexión de Filipinas. La Independencia de Estados Unidos (1776) permite constituirse en unidad federada, que se expandirá mediante compras, guerras y conquistas hasta obtener un territorio varias veces mayor que el 'originario' de las 13 colonias. Este expansionismo desatado hará alzar la voz de William. Su diagnóstico de la naturaleza humana es lapidario: somos belicosos y depredadores y para esto no hay 
remedio en la paz universal o el desarme general, sólo paliativos, sólo una 'medicina preventiva', consistente en llevar pacifistas al poder y educar a los funcionarios en la responsabilidad (Banquete para la Paz, 1904).

En El equivalente moral de la guerra (1906) diagnostica la Historia como "un baño de sangre"; la guerra como 'romance' de la historia, pues ningún hombre duda en pagar los impuestos de guerra y eso lo muestra el presupuesto de todas las naciones. Además, la humanidad misma está nutrida de dolor y temor, siendo el deber de los pacifistas profundizar el punto de vista ético y estético de sus enemigos porque los deberes, penalidades y sanciones descritas en las utopías son todas muy débiles y tímidas para afectar a los militaristas: "devotamente creo en el reino de la paz y en el gradual advenimiento de una suerte de equilibrio socialista. La visión fatalista de la función de la guerra es un sin-sentido para mi” (p. 6).

En Los ideales de la vida (1899) propone para los estadounidenses un "evangelio del abandono", una moral austera y abandono a la voluntad de Dios, un ideal de calma, armonía y compostura. Asimismo, propone respeto por lo sagrado de la vida ajena y la intimidad inescrutable del prójimo, en mutua tolerancia y respeto por los sentimientos, creencias y costumbres, como el fundamento más firme de la libertad entre colectividades.

Postula que el ideal que enaltece no está en la mente sino en la acción y el sacrificio. El ideal debe dominar la vida, determinando la conducta para ser real y verdaderamente un fin (James, 1899).

En Valores sociales (1907), conferencia dictada en Radcliff College (femenino), plantea que los estudios superiores ayudarán a "reconocer un hombre de bien cuando lo vean".

Granville Stanley Hall (1844-1924). Sus trabajos se circunscriben fundamentalmente a la Psicología evolutiva. Es el primero en abordar sistemáticamente la conceptualización de la adolescencia apoyando la Teoría de la Recapitulación (la ontogenia recapitula la filogenia). Asimismo, sus preocupaciones atañen a la realidad política, determinando como rasgo del buen ciudadano el deber de cultivar el idealismo (Hall, 1908).

Destaca la función de este idealismo recuperando a Platón como un artista genial, que releva el ideal de lo bello-bueno, combinando antiguas filosofías con los insights profundos de sus días, buscando la regeneración moral y contagiando con la pasión por su ideal (Hall, 1885).
Inspiración ética de un ideal que se concreta en 13 atributos propios de la tarea del buen ciudadano: conocer las leyes, como deber comunitario y obligación moral; obedecer al espíritu y a su letra; pagar impuestos; asistir a reuniones; votar siempre inteligente y moralmente; aceptar los cargos que de allí deriven pues la voz del pueblo es el llamado de Dios; expresar lo que estime está mal; poseer orgullo local y patriotismo; casarse, mantener su casa, ser cabeza del hogar y padre de los niños; dejar dinero a la comunidad y dar la vida por el país - toda vez que la guerra sea necesaria-; votar por el mejor y no por el partido como principios administrativos; y participar en la escuela y su administración (Hall, 1908).

¿Cómo estar en desacuerdo con estas arduas tareas que Hall confiere al buen ciudadano? ¿Excluye algo o a alguien? Las condiciones de 'contexto' hacen inaudibles (iinauditas?) las voces de trabajadores, negros y mujeres sin derechos ciudadanos.

En su extenso análisis de Philosophy in the United States (1879) criticará fuertemente el método de adoctrinamiento con ortodoxias que cierran el interés especulativo. Así, las grandes cuestiones de la psicología y la metafísica quedan abiertas, la naturaleza psicológica y el origen de la conciencia son cuestiones que han provocado muy poco interés, enfatiza Hall.

Para Hall (1908), durante el último cuarto de siglo, América ilustra el poder de la mente humana sobre la naturaleza: St. Louis, ciudad joven y extensa, centro geográfico y comercial, muestra al hombre creativo y hacedor del mundo.

Estados Unidos de Norteamérica, que ha heredado un lenguaje ya listo (ready-made) y una rica literatura que no ha desarrollado, es apta para ser superficial en el pensamiento y poco profunda en el sentimiento.

El Domingo, institución filosófica, será día de descanso, de vida familiar e introspección, que dará seriedad y perfilará el carácter, enseñando autocontrol, autoconocimiento, auto-respeto como el más alto producto intelectual e inspiración.

Finalmente, y si de acuerdo a la nueva psicología, la parte activa de nuestra naturaleza es esencial en la cognición y si toda verdad posible es práctica, ¿es posible esperar de esos materialismos de la fe y los negocios, el fundamento para una maduración del insight filosófico y/o la armonía intelectual entre las diversas capas de la vida nacional?

Stanley Hall en su larga y exitosa vida profesional, además de sus acciones para el desarrollo e 
institucionalización de la nueva psicología -fundador de la American Psychological Association y el Journal of American Psychology-se interesó en el nuevo mundo de ideas: es el primero en abrirse al Psicoanálisis invitando a Freud a dictar aquellas legendarias conferencias en la Universidad de Clark.

James Mark Baldwin (1861-1934): Circunscribiendo su pionero trabajo al estudio empírico de la conducta infantil, Baldwin propone una teoría concerniente al rol de la sociedad en el desarrollo moral. Su radical compromiso con el espíritu evolucionista de la época, lo orienta a fundar una "epistemología genética" donde el razonamiento moral sirve de ejemplo para sostener que la biología, la mayor parte de las veces, se someterá al influjo del legado social. Ya en Elementos de Psicología (1893) orienta el estudio de la ética hacia el sentimiento ético como elemento de emociones relacionales, un coeficiente moral que experiencialmente se asocia con predicados buenos y malos. Su cualidad moral es una generalización de las acciones posibles, pero forzadas cuando se trata de sostener que no toda acción sería moral.

Las acciones morales deben ser actos voluntarios o actos de voluntad no aislables en la conciencia y en la conducta, ni caracterizables de buenos o malos simplemente. Las acciones morales son armoniosas entre sí en relación con un ideal. Un acto moralmente indiferente es un acto que está aislado, válido sólo para quien lo realiza y no representa nada en los actos complejos constitutivos de la conducta social. Sólo cuando engendra una serie de relaciones más o menos conscientes, éste se hace moral.

Para Baldwin (1894) la moralidad se transmite socialmente, vía instrucción y ejemplo, depositándose en los "hábitos personales del niño" a través de la emergencia de un sentido de self personal que, idealmente, encarnará las costumbres y tradiciones de su "raza", correspondiendo a un ideal del self, en el cual la obediencia e imitación, la recompensa y el castigo desempeñarán un papel fundamental.

Baldwin (1897) describe el desarrollo moral: el niño posee inicialmente un yo sensible -una masa de material personal sugerido por los otros- y que elabora en un todo más o menos sistemático a través de sus propios actos imitativos, un self del hábito o self habitual. De este modo, constituye un 'alter ego' distinto al 'ego' privado constantemente modificado por influencias de su entorno social.

La dialéctica del self y la rica gama de relaciones sociales o 'socius', va desde la insuficiencia o inadecuación entre sus selves hasta un sentido del socius como amplio lazo de unión con diferentes pensamientos privados acerca de sí mismo. Esta es realmente la cuestión fundamental para Baldwin: una evolución del sentido ético en términos psicológicos.

Plantea que "el niño no hereda el contenido de la moralidad" (Baldwin, 1899, p. 48), confía en la instancia de la vergüenza social por su agudo significado ético y la relaciona con el desarrollo del sentido del sí mismo. El sentido de ideal moral es un ideal perfecto posible en el self personal como en el social; es una voluntad de actuar armoniosamente. El sentido de obligación es justamente la carencia de tal armonía, producto de discrepancias reales entre los selves.

Para Baldwin (1901), la ética requiere un tratamiento filosófico más que meramente científico. No obstante, la concibe como la ciencia del ideal en el carácter, a veces como "arte" de la conducta, semejante a la lógica en tanto 'arte del pensamiento'.

En general, Baldwin sugirió que los individuos se acercan a situaciones en un equilibrio de hábitos y comportamientos sociales, incorporando nuevas ideas a lo largo del camino.

La ausencia de ley -aunque fuese en un reino elevadísimo- es un estorbo en cualquier doctrina sobre el significado de la vida ética humana. El padre, la madre, las personas encargadas de su cuidado son la primera personificación de la ley social y de su conducta surge el primer estándar ético. La iglesia, el estado, el voto popular, el rey, la literatura de un período son depósitos selectos del ser ético; la opinión pública será nuestra moderna expresión para la forma más penetrante de este espíritu.

El niño es apropiadamente social sólo si se somete. Luego él mismo impondrá la ley familiar a los otros miembros. Así la ley llega a ser ley no escrita, heredada, pues impregna el pensamiento del mejor self en cada miembro del grupo social (Baldwin, 1897).

Si lo que llamamos 'socius' implica negaciones de sus selves insociables (el de interés privado y el de acomodación), favoreciendo una ley puesta por otro, esta actitud debe convertirse en tendencia hacia una ley mayor, a buscar cierto punto por hábito alguna autoridad superior. Pero es hábito de actuación (acting), no hábito de acción (action). Esta relación entre moralidad y hábito implica infracciones dolorosas y violaciones de viejos hábitos de acción. Es un hábito de violar hábitos. Lo correcto imita un self más extenso, cuyos mandatos corren contra las tendencias de nuestros selves parciales. 
Este gran partidario del evolucionismo, muere en su 'autoexilio' en París, olvidado junto a su enorme producción teórica, tras un affaire vergonzoso en un burdel que destruyó su prestigio académico en una época en que -aún no tan evolucionada- la doble moral inquisidora podía destruir el honor y la credibilidad de un caballero 'relajado': es expulsado del 'socius' de su entorno. Pero la Patria en guerra lo llama para fundar la Liga Naval, su self ideal acepta el trabajo y amnistía. Rehabilitado su honor publicará una serie de artículos y sus experiencias en torno a dos guerras: la de Secesión y la Primera Guerra Mundial (Horley, 2001).

\section{Chile: Segunda Trilogía}

A continuación presentamos a nuestros connacionales: Hernán Larraín Acuña, sacerdote jesuita que en su "mensaje" develará una ética premonitoria para el análisis que nos convoca. Posteriormente, Salvador Cifuentes, ex detective y psicólogo, traerá a nuestro territorio la naciente corriente humanista de la psicología; finalmente, Sergio Yulis, destacado investigador, clínico y docente, primer psicólogo chileno doctorado en los Estados Unidos.

Hernán Larraín Acuña (1921-1974). Formado en la Compañía de Jesús, tradicional escuela de pensamiento y acción religiosa, es quizás la figura más categórica de nuestra muestra. Entre los cargos que detentó se encuentran: primer secretario de la Academia Chilena de Ciencias Sociales, Políticas y Morales (1964), Rector de la Universidad Católica de Valparaíso, Director de la Revista "Mensaje" y Director de la Escuela de Psicología de la Universidad Católica de Chile.

Especializado en psicología en Munich, Alemania, es designado en 1957 Director del Departamento de Psicología de la Universidad Católica de Chile, a la que le imprimirá una orientación fenomenológicadescriptiva, abiertamente contrastante con la línea más positivista y pragmática de la Universidad de Chile (Winkler, 2004).

Los años sesenta, apogeo de las ideologías de cambio, ideas revolucionarias y utopías, traen un resurgimiento vigoroso de las concepciones progresistas, el debate intelectual, el desarrollo y conocimiento de instrumentos conceptuales no sólo para el diagnóstico sino como modelos de sociedad deseables y el modo de lograrlo; el Concilio Vaticano II será el símbolo de renovación e innovación del mundo cristiano. En Chile, el déficit de pensamiento cristiano en materia social y política era evidente: ideas predominantemente conservadoras y bastante ideológicas en claro desfase entre las potencialidades del cambio, la modernización y la democratización (Garretón, 1993, p. 299). Los jesuitas no exentos de contradicciones y ambigüedades, jugarán un papel crucial en el pensamiento y la acción sociales, sin el carácter diletante del mero análisis social al apartarse del paradigma norteamericano de la modernización y del marxista de la dependencia.

A propósito de la Revolución en América Latina, Larraín escribe:

"Soplan aires revolucionarios. Una inmensa mayoría está tomando conciencia de su fuerza, de su miseria, y de la injusticia de ese 'orden' político, jurídico, social y económico, que se le obliga a aceptar; y esa mayoría no está dispuesta esperar más. (...) Lógicamente esta masa deseosa de 'revolución' se inspira en la única ideología revolucionaria que encuentra a su alcance: la ideología marxista... Año a año aumenta la población de América Latina en millones, (...) Millones de hombres desnutridos, analfabetos, hacinados en tugurios vergonzosos... Esto y no otra cosa significan la 'Revolución en América Latina'. (...) Todos somos hermanos, todos tenemos el derecho y el deber de realizar nuestra misión y tarea humana, todos debemos vivir humanamente. Debemos, por consiguiente, instaurar un orden político, un orden jurídico, social y económico que realice, efectivamente, el 'bien común', el bien de todos, aunque tengamos que sacrificar ciertos bienes 'particulares'... luchar leal y esforzadamente por el 'Bien común' defendiendo, al mismo tiempo, el carácter sagrado e inalienable de la persona humana... Veracidad y audacia serán virtudes que necesitaremos. (...) No olvidemos que sólo unidos a Cristo podemos 'Cristianizar' la revolución en marcha.”(Larraín, 1962 , pp. $155-164$ y pp. 589-592).

Larraín (1966) realiza un reconocimiento abierto al recientemente asesinado sacerdote colombiano Camilo Torres. En una entrevista publicada en la revista Ercilla, defiende enérgicamente a este religioso "apóstata" que, después de su fracaso por alcanzar una mayor justicia social por medios democráticos y optando por la lucha armada, había combatido como guerrillero contra el Gobierno de su país.

En el campo de la Psicología como "ciencia" encontramos en sus múltiples escritos y editoriales sólo algunas referencias al Malestar en la Cultura (Freud, 1907). Malestar y deseo de cambio animan aquellos años y él lo hace desde la "Revolución en 
Libertad", una transformación no marxista de la sociedad. El sacerdote Larraín usará la tribuna de la Revista Mensaje para hacer explícitas sus posiciones ante la cuestión social, política y moral: reforma agraria, reforma educativa y papel de la juventud.

También, días antes del golpe militar, el padre Larraín asegura precursoramente: "Es importante que el poder derive de las bases y esté depositado en las bases, eso es auténtica democracia"... "Chile propuso un nuevo camino y abrió un interrogante a la teoría y a la práctica de la revolución. Se traicionaría a Chile y al Tercer Mundo cerrando ese interrogante con metralletas y tanques" (Larraín, 1973, pp. $210-211$ ).

Este sacerdote que consideraba la fuerza como el peor de los argumentos, muere en 1974 pocos meses después del Golpe de Estado.

Salvador Cifuentes (1928-1994). La semblanza hecha por uno de sus discípulos, Edgardo Rivero (1994), lo presenta como un laico que se mantiene fiel a un concepto de ser humano en medio de la oscuridad y del nihilismo, delicado y silencioso en la esperanza de un nuevo paradigma. Gabriel Reyes (2004), por su parte, rescata su gran afición a la lectura, lo define como un pensador y confirma que se dedicó a la docencia y la clínica, sin dejar su pensamiento por escrito.

Salvador Cifuentes rescata e importa el concepto de persona como centro de libertad y responsabilidad, compartiendo con Rogers, Maslow y Buber una actitud antidogmática, de aceptación incondicional de lo humano de sus colegas, al respetar y auspiciar todas las posturas por la coexistencia de paradigmas en la Escuela de Psicología de la Universidad de Chile; consecuentemente abandona Chile en 1979 por no poder silenciar su postura antidogmática en el Consejo de Facultad, intervenido militarmente. En 1993, vuelve al ataque por restablecer aquella Escuela.

Sólo disponemos de hebras fugaces asentadas en un obituario (Rivero, 1994), nada escrito de su mano, sólo la desgrabación de un foro sobre psicoterapia (Cifuentes, Coddou \& Hoffmann, 1987).

Transmitir es, para Salvador Cifuentes, "señalar de algún modo" la experiencia terapéutica como un tipo de relación interpersonal, convencido que el verdadero agente de cambio es la propia persona y el rol del terapeuta es nada más que ser liberador de dicha potencialidad, implicando que el terapeuta debe "descartar o minimizar en su operar terapéutico su propio marco de referencia con todo el bagaje de teorías e ideas sobre lo que sucede en el paciente" para comprenderlo empáticamente e instrumentalizar el proceso de cambio.

Cifuentes sólo utiliza el vocablo "persona”, y pasará por sobre la mercantilista acepción de la palabra cliente. Con un laicismo loable asume únicamente que allí, tras la 'persona', hay una comunicación que 'reorganizará su campo aperceptivo", liberándose para devenir una Persona.

¿Un libre pensador que usa de su libertad para posibilitar la liberación del paciente de sus representaciones negadas o deformadas? ¿Un laico que busca la confluencia en la tolerancia?

No hay textos que avalen su pensamiento, sólo el quehacer, la labor de transmitir a sus discípulos una herencia "socrática".

Sergio Yulis (1936-1980). También es escasa la información sobre Yulis, joven promesa de la Psicología chilena, en la estela de su trayectoria y formación en Estados Unidos: obtiene la Beca Fulbright del gobierno para estudiar en la Universidad de Iowa, realizando el Master en 1967 y el Doctorado en psicología clínica en 1968.

En 1969 regresa al país y un año después asume como director de la Escuela de Psicología de la Universidad Católica, mientras paralelamente dirige las cátedras de psicoterapia en la Universidad de Chile. Impulsa decididamente el análisis del comportamiento, la investigación rigurosa en la disciplina (Miranda \& Navarro, 1995) y la formación en psicoterapia, imprimiendo una nueva etapa en el desarrollo de la psicología chilena (Winkler, 2004).

Dirigió investigaciones en diversos temas: alcoholismo y drogadicción, sexualidad humana y disfunciones sexuales; evaluó y desarrolló la terapia conductual y fomentó habilidades en profesionales de la salud. Investigó y publicó acerca de las relaciones entre excitabilidad sexual, habilidad para imaginar e introversión-extraversión (Harris, Yulis \& Lacoste, 1980) o de la Comunicación: teoría y técnicas de tratamiento (Yulis, 1982).

Dubrovsky y Harris (1980) lo recuerdan "comprometido tanto con el esfuerzo de aminorar el sufrimiento humano, como el de desarrollar las habilidades del profesional de la salud (...) también como un hombre que tuvo la valentía de comunicar su humanismo esencial" (p. 88).

La remembranza de Miren Busto (2000), muestra a Yulis interesado en la cuestión de la ética profesional: su énfasis en la formación del psicólogo como una cuestión ética, pues un psicólogo clínico debe estar consciente y considerar todo daño evitable y, 
en calidad de especialista, priorizar lo que beneficia, lo que amplía y abre alternativas. Clínica entonces de lo cerrado hacia lo abierto, conceptualización del daño como limitación y cierre impuestos en la inmovilidad de la falta de alternativas: un daño inducido que el clínico no puede repetir. “...El ambiente terapéutico no es un lugar, no es un tiempo tampoco. Es un límite relacional”.

Para Montesinos (2000) lo marcará su calidad de maestro, que lo inició en la rigurosidad del conductismo con la asesoría a profesoras para el manejo de la conducta disruptiva en la sala de clases.

La vida de Yulis se cierra tempranamente. En vísperas de su proyectado retorno a Chile y de su reinserción en el mundo académico, es hospitalizado en Montreal. La expectativa es defraudada por su muerte en la sala de operaciones.

\section{Comentarios}

Es llamativa una primera y radical diferencia entre los personeros usamericanos y chilenos: la no práctica del hábito de escritura como modo de interlocución, expresión o despliegue de los conceptos y sus distinciones. Representantes de las iglesias protestantes para las cuales la lectura del libro sagrado era esencial en su práctica religiosa y ritual, enfrentados a "una Iglesia Católica latinoamericana tan letrada en su cúpula y tan oral en su pastoral y en su feligresía" (Serrano \& Jaksic, 2000, p. 460). En este sentido podemos suponer nuestra sociedad como "ágrafa", en continuidad con la tradición de recepción y herencia de saberes por vía oral, por el camino de la praxis, la imitación y el ejemplo.

Una larga tradición escritural, fundamentalmente en el ámbito de la creación poética y de otras disciplinas que se apegaron y apoyaron en las letras: todo el campo de lo jurídico desarrolló su oficio ejercitando la argumentación por escrito. En las Universidades exigieron de sus egresados la realización de una tesis de grado que debía cumplir no sólo las normas disciplinares sino también demostrar la capacidad de redactar las ideas en forma coherente.

Es nuestra expectativa hacer aparecer los nexos entre política y ética a través del realce de aquellos textos que -como psicólogos- nos entregan. Búsqueda intencionada para detectar si esta 'ciencia' -la psicología- es en verdad 'avalórica' y ahistórica y palpar sus consecuencias en la realidad "social" por supuesto y, por lo tanto, política.

Lógica darwiniana es la que sigue Baldwin en su evolucionismo; por cierto más laico, consciente de sí y buscando, antes que Piaget, la respuesta en sus propias hijas. Develando en una postura artística o "metafísica" los códigos y rincones que hacen de la observación una ciencia y de su "producto" la naturaleza de una herencia social. Su conciencia no le permitirá asumir sus propios hábitos impracticables y, siguiendo el llamado "políticamente correcto" hacia un auto exilio, será coherente con las leyes sociomorales de la época que lo condenaron tras su detención en Baltimore.

James y Hall, herederos de la 'aristocracia protestante' y descendientes del Mayflowers, buscan la delimitación de la psicología dejando la ética en el campo de la metafísica. James inicia la partida para volver a ser un filósofo hasta el fin de sus días, pero su quehacer político lo muestra actuante y 'protestante', anti-imperialista.

Hall, abierto a las contradicciones abre la Universidad de Clark a las charlas de Freud e instala, además los deberes del ciudadano, la cuestión de la psicología y la adolescencia; una problemática que emergió de su pluma para constituirse hoy en la pregunta ¿qué es un adolescente? ¿quiénes no adolescen? Patriotismo filantrópico y lleno de fe, verdad y cogniciones prácticas. Patriotismo como un ideal, como sentimiento filosófico que posibilita el insight filosófico y la praxis de intelectualizar armónicamente lo heteróclito.

Nuestros psicólogos anglomericanos estarán ligados fundamentalmente a la docencia e investigación en la academia. De allí, hombres y mujeres, explicitarán sus trabajos, no así los chilenos, pues tenemos en ellos el interesante contrapunto entre aquel dedicado de lleno a plasmar sus opiniones y las de sus jerarquías a través de la revista Mensaje y este silenciosamente dedicado al trabajo investigativo de la Psique o del crimen, sin escribir palabra alguna en teoría y, entre los dos, a Sergio Yulis, experimentalista heredero de la cultura psicológica empírica usamericana promueve y explicita las normas éticas en la formación de psicólogos/as.

Nuestra diferencia fundamental es la urgencia de la necesidad de formar psicólogos/as, necesidad también de educación. Con pocos años de diferencia se crea la Escuela de Psicología de la Universidad de Chile y la Escuela de Psicología de la Universidad Católica. La metafísica quedará en este caso prácticamente sin posibilidad de discusión.

Los laicos guardan silencio como psicólogos y el psicólogo Larraín habla sólo como sacerdote militante que, pese a aborrecer el militarismo, reconoce 
el compromiso de sus hermanos cuando se trata de luchar por la "justicia social".

Cifuentes aporta a la psicología chilena la importación del concepto de persona. La terminología estadounidense adjunta la noción de 'cliente' que conflictuará a la psicología latinoamericana de aquellos años ajenos aún del 'mercantilismo' global. Como profesional estará preocupado y ocupado por el proceso, por la operación e instrumentalización del cambio, dejando a sus discípulos/as la tarea de generarlos.

La voz de Larraín es escuchable. De Sergio Yulis y Salvador Cifuentes tenemos tan sólo sus semblanzas, artículos 'in memoriam'.

¿Es posible pensar el reconocimiento de nuestras filiaciones teóricas como 'transferencias' ideológicas $\mathrm{y}$ fantasmales a un discurso que provee de lugar y de posición en las heterodoxias y mestizajes latinos? ¿Son sólo armas teórico-prácticas sin incidencia política?

Esperamos haber transmitido al menos los ecos difusos de sus mensajes.

\section{Referencias}

Baldwin, J. (1893). Elements of psychology. New York: Holt. Versión española: Elementos de Psicología (1958). Madrid: La España Moderna.

Baldwin, J. (1894). Mental development in the child and the race: Methods and processes. New York: Macmillan.

Baldwin, J. (1897). The genesis of the ethical self. Philosophical Review, 6, 225-241. Recuperado el 29 Agosto de 2003, desde: http://spartan.ac.brocku.ca/ lward/Baldwin/Baldwin_1897. html

Baldwin, J. (1899). Social and ethical interpretations in mental development. New York: Arno.

Baldwin, J. (1901). Dictionary of philosophy and psychology. New York: MacMillan.

Bobbio, N. \& Matteucci, N. (1982). Diccionario de política. México: Siglo XXI Editores.

Buelna, M. E. (1990). Modernidad y contramodernidad de la Compañía de Jesús. En Constelaciones de la modernidad (pp. 47-78). México: UAM.

Busto, M. (2000). “Que veinte años no es nada”. Recuerdos de un formador de terapeutas. Revista Terapia Psicológica, 7(34).

Cano, S. (2000). Propuesta ético-politica de Hannah Arendt. Recuperado el 26 de Mayo de 2004, desde: http://www.salvador. edu.ar/vrid/publicaciones/revista/ccabildo.htm

Cifuentes, S., Coddou, F. \& Hoffman, L. (1987). Foro Nacional, Psicoterapia. Revista Terapia Psicológica 6(9), 7-16.

Dubrovsky, B. \& Harris, R. (1980). In Memoriam. Sergio Yulis, Ph. D. (1936-1980). Revista Chilena de Psicología, 3(2), 87-88.

Espíndola, E. (1993). Editorial. Revista Mensaje, 42(420), 177-178.

Freud, S. (1907). El malestar en la cultura. En Obras completas Vol. IX. Buenos Aires: Amorrortu.

Garretón, M. (1993). Los jesuitas y el pensamiento social de los sesenta en Chile. Revista Mensaje, 42(420), 298-303.
Giannini, H. (1997). Del bien que se espera y del bien que se debe. Santiago: Dolmen.

Glasser, B. \& Strauss, A. (1967). The discovery of grounded theory. Chicago: Aldine Publishing Company.

Gonzalbo, P. (1990). El currículum oculto en los colegios novohispanos de la Compañía de Jesús. En Constelaciones de la Modernidad (pp. 79-98). México: UAM.

Hall, S. (1879). Philosophy in the United States. Mind, 4, 89105.

Hall, S. (1885). The new psychology. Andover Review, 3, 120$135,239-248$.

Hall, S. (1908). 100th Anniversary of the incorporation of the town of West Boylston. Massachusetts. Held in the town hall, January 30th. Recuperado el 9 de junio 2002, desde: http:// webpages.charter.net/jean_costello/documents/Address $\% 20 \mathrm{~b}$ y\%20Dr.\%20G.\%20Stanley\%20Hall.pdf.

Harris, R., Yulis, S. \& Lacoste, D. (1980). Relationships among sexual arousability, imagery ability, and introversión-extraversion. The Journal of Sex Research, 16(1), 72-86.

Horley, J. (2001). Alter "the Baltimore affair": James Mark Baldwin's life and work, 1908-1934. History of Psychology, 4(1), 24-33.

James, W. (1892). Psychology. A briefer course. Nueva York: Harper. Versión española: Compendio de psicología (1947). Buenos Aires: Emecé.

James, W. (1899). Los ideales de la vida. Versión española: de Soldevilla, C. (1944). Buenos Aires: Editorial Americalee.

James, W. (1904). Banquete para la paz [Remarks at the Peace Banquet]. The Atlantic Monthly, 94, 845-847. Recuperado el 29 de Junio de 2003, desde http://www.mory.edu/EDUCATION/mpf/jamesPeace1904.html

James, W. (1906). The moral equivalent of war. Recuperado el 22 de Diciembre de 2003, desde: http//www.constitution. org/wj/meow.htm

James, W. (1907). The social value of the college-bred. Recuperado el 22 de Diciembre de 2003, desde: http://www.mory. edu/EDUCATION/mpf/jaCollegeBred.html

Larraín, H. (1962). Revolución en América Latina. Revista Mensaje, Diciembre, 589-592.

Larraín, H. (1966, 9 de marzo). Entrevista. Revista Ercilla.

Larraín, H. (1973). Hacia una democracia. En F. Cid (Ed.), El humanismo de Hernán Larraín II. Santiago: Instituto Chileno de Estudios Humanísticos.

Lechner, N. (2002). Las sombras del mañana. Santiago: LOM Ediciones.

Leturia, J. (1993). 1993-1593=400. Itinerario de una aventura. Revista Mensaje, 42(420), 209-214.

Miranda, N. \& Navarro, M. (1995). La historia de la psicología en Chile referida a algunos aspectos de la formación profesional. Tesis para optar al título de Psicólogo, Escuela de Psicología, Pontificia Universidad Católica de Chile, Santiago, Chile.

Montero, M. (2001). Ética y política en psicología. Athenea Digital, No. 0- abril. Recuperado el 24 de Octubre de 2001 desde: http//www.blues.uab.es/athenea/Revista/Articulos/ maritza.htm

Montesinos, L. (2000). La herencia de Sergio Yulis: Una perspectiva personal. Revista Chilena de Psicología, 21(1), 105-110.

Morse, R. (1982). El espejo de próspero. Un estudio de la dialéctica del Nuevo Mundo. México: Siglo XXI.

Reyes, G. (2004, 9 de marzo). Entrevista realizada por María Isabel Reyes.

Rivero, E. (1994). A Salvador Cifuentes: In memoriam. Terapia Psicológica, 5(22), 72-73.

Serrano, S. \& Jaksic, I. (2000). El poder de las palabras: La Iglesia 
y el Estado Liberal ante la difusión de la escritura en el Chile del siglo XIX. Historia, 33, 435-460.

Strauss, A. \& Corbin, J. (1994). Grounded theory methodology. An overview. En D. Norman \& I. Lincoln (Eds.), Handbook of qualitative research. Thousand Oaks: Sage Publications.

Winkler, M. I. (2004). Pioneras sin monumentos: Mujeres en la historia de la psicología en Estados Unidos de Norteamérica, Argentina y Chile durante las tres primeras décadas del desarrollo de la disciplina. Tesis para optar al grado de Doctora en Estudios Americanos, IDEA, Universidad de Santiago de Chile, Santiago, Chile.
Winkler, M. I., Pasmanik, D., Wolff, X., Reyes, M. \& Vargas, H. (2007). Perspectivas en ética y género en la obra de pioneros y pioneras de la Psicología. Revista Latinoamericana de Psicología, 39 (3) 523-535.

Yulis, S. (1982). Comunicación: Teoría y técnicas de tratamiento. Terapia Psicológica, 1(1), 7-15.

Zinn, H. (2003). A people's history of the United States (1492present). New York: Harper Collins.

Fecha de recepción: Octubre de 2007

Fecha de aceptación: Abril de 2008 